\title{
Development of Save Antibacterial Finish for Socks and Kitchen Fabrics
}

\section{Erana LA*}

Wollo University, Kombolcha, Ethiopia

\begin{abstract}
In the present study, commercial socks and dishcloth made up of cotton was treated with a safe natural antibacterial agent, Neem (Azadirachta indica) leaf essential oil to overcome the growth of bacteria on these fabrics which would in turn prevent the diseases caused by them. Nutrient agar (consisting of peptone, yeast extract, sodium chloride and agar) as a food media for bacterial growth was used to expose the fabrics to bacterial growth. The socks and dishcloth exposed to the above environments support the growth of bacteria/genus, namely Pseudomonas aeruginosa, Pseudomonas fluorescents, Enterococcus species and Streptococcus species. Antibacterial finish is imparted using two different concentrations, 3\% owm and 5\% owm of Azadirachta indica, both in the absence and presence of citric acid, following pad-dry-cure technique. Antibacterial tests carried out following disc diffusion method on these treated (unwashed) cloths proved that the Azadirachta indica acts as a good antibacterial agent. The durability test carried out on the treated samples reveal that the antibacterial treatment carried out in presence of citric acid could withstand 3 washing cycles whereas, the samples treated in the absence of the acid could not withstand even a single wash.
\end{abstract}

Keywords: Socks; Dishcloth; Azadirachta indica; Antibacterial treatment; Antibacterial finish, Durability test

\section{Introduction}

The atmosphere is rich of spores of bacteria and fungi. These microbes play an important role in many biological sequences. Without them, life as we know it would be an imaginable. They clean the environment, they provide the fertility of soil, they are necessary even for the production of cheese, yogurt or beer. By the same process, however, microbes can damage and destroy a great number of important and valuable materials. The microbes themselves or their metabolism products can lead to deterioration of textile materials and can cause a variety of illnesses [1].

All articles of apparel and home textiles are susceptible to problems of hygiene in daily use [1]. When fibers are subjected to attack by microbes, specific properties such as tensile strength and impermeability are lost [2]. To solve these problems and keep users from bacterial dangers the textile wet processors have started to treat fabric with antimicrobial agents. Antimicrobial agents are synthetic or natural substances that can either kill or inhibit the growth of microorganisms.

Different synthetic chemicals have been used as antibacterial agent to produce antimicrobial cotton fabrics. But in recent times as the knowledge of peoples is increasing about the environmental loads and some side effects associated with synthetic chemicals, researchers are trying to improve the antimicrobial properties of cotton fabric using natural substances. Natural substances are usually eco friendly and do not impose side effect on usage.

Azadirachta indica is one of the natural products which are known to show antibacterial activity against different bacteria [3]. In this project work the antimicrobial property of Azadirachta indica treated socks and dishcloths made up of cotton fabrics are studied. Development of antibacterial textiles in developing countries like Ethiopia is at a very early stage. The present study shows the indispensability of the concept of antibacterial finishing of socks and dishcloth.

\section{Materials and Equipments}

\section{Materials}

In the study cotton socks and dish cloths were selected. A fabric sample obtained from the commercial market was used for treatment with antimicrobial agent. The specifications for the fabric used in the experiments carried out are shown by the table below (Table 1).

Azadirachta indica (Neem) leafs are obtained from kombolcha road ways. To study the antimibacterial effect of Azadirachta indica on treated cotton socks and dishcloths fabric samples four Bacteria which are prone to socks and dishcloths namely Pseudomonas aeruginosa, Pseudomonas fluorescents, Enterococcus species and Streptococcus species were used in the study. Nutrient agar (consisting of peptone, yeast extract, sodium chloride and agar) as a food media for bacterial growth was used. As antimicrobial agent Azadirachta indica leaf oil is obtained by using soxlehet extraction (Table 2).

\section{Equipments}

Petri dish: This equipment is used for holding nutrient agar, bacteria and the sample of fabric samples.

Sterilizing machine: This is used for sterilizing materials and equipments used in the testing procedure. Two types of sterilizing

\begin{tabular}{|l|c|}
\hline Type of weave & Terry pile \\
\hline Warp count & $10 \mathrm{~s} \mathrm{Ne}$ \\
\hline Weft count & $10 \mathrm{~s} \mathrm{Ne}$ \\
\hline Ends per cm & 13.4 \\
\hline Picks per cm & 13.4 \\
\hline Warp crimp & $8 \%$ \\
\hline Weft crimp & $12 \%$ \\
\hline Weight per unit area & $220 \mathrm{~g} / \mathrm{m}^{2}$ \\
\hline Fabric cover factor & 22.43. \\
\hline
\end{tabular}

Table 1: Commercial grade $100 \%$ cotton dishcloth with above specifications.

*Corresponding author: Erana LA, Wollo University, Kombolcha, Ethiopia, Tel: (+251) 33-119-0712; E-mail: lamiamanuel@gmail.com

Received April 22, 2017; Accepted June 01, 2017; Published July 05, 2017

Citation: Erana LA (2017) Development of Save Antibacterial Finish for Socks and Kitchen Fabrics. J Textile Sci Eng 7: 306. doi: 10.4172/2165-8064.1000306

Copyright: (c) 2017 Erana LA. This is an open-access article distributed under the terms of the Creative Commons Attribution License, which permits unrestricted use, distribution, and reproduction in any medium, provided the original author and source are credited. 


\begin{tabular}{|l|c|}
\hline Type of knit & Rib \\
\hline Yarn count & $30 \mathrm{~s} \mathrm{Ne}$ \\
\hline Loops density & 10 \\
\hline Yarn crimp & $5 \%$ \\
\hline Weight per unit area & $10^{2} \mathrm{~g} / \mathrm{m}^{2}$ \\
\hline Fabric cover factor & 21.31. \\
\hline
\end{tabular}

Table 2: Another commercial grade $100 \%$ cotton socks with above specifications was used for the application of herbal extract.

machines were used, steam and dry sterilizer. Steam sterilizer is used for sterilizing the nutrient agar solution. Dry sterilizer (incubator) used during preparation of Petri dish in order to make free from different micro organisms found in the environment and incubation of the bacteria.

- Pressure cooker: It is used for degumming of silk coccons.

- Padding machine: It is used to apply the degummed silk solution onto the fabric.

- Mini dryer: It is used for drying and curing of the treated samples.

- Others: Stove, refrigerator, thermometer, PH tester, scissors, weighing balance etc.

\section{Methods}

\section{Extraction of Azadirachta indica leaf oil}

Solvent extraction technique using Soxhlet apparatus was employed to extract Azadirachta indica leaf oil. $15 \mathrm{~g}$ of Azadirachta powder was taken in the thimble and $300 \mathrm{~mL}$ of ethanol-water mixture was added to the extraction flask. The complete assembly of the apparatus was kept on a heating mantle and its temperature was adjusted to boiling and taking out cooling is done every $15 \mathrm{~min}$. The extraction was continued for 3 hours. Finally, the filtrates oil is pooled and kept.

\section{Treatment of cotton fabric with Azadirachta indica oil}

For $5 \mathrm{~g}$ of socks and kitchen fabric $50 \mathrm{~mL}$ of extracted oil was used. the fabrics were treated with Azadirachta indica oil by using pad-drycure process using the following procedure. The padding is carried out with three pad three nips and the squeezed fabric sample was dried at $60^{\circ} \mathrm{C}$ for $3 \mathrm{~min}$ and curing is performed at different temperatures $\left(130^{\circ} \mathrm{C}, 150^{\circ} \mathrm{C}, 165^{\circ} \mathrm{C}\right)$ for $3 \mathrm{~min}$.

\section{A) Procedure for agar zone of inhibition test}

1. Materials like petri dish, cotton swab and other equipments used for the testing process must be sterilized.

2. A nutrient agar solution is prepared by using $36 \mathrm{~g}$ of nutrient agar (consisting of peptone, yeast extract, $\mathrm{NaCl}$, agar) with 1 litter of water.

3. The nutrient solution is sterilized in a steam sterilizer machine at a temperature of $121^{\circ} \mathrm{C}$ for $15 \mathrm{~min}$.

4. 16 petri dishes were prepared with sterilized nutrient solution and kept until it is solidified.

5. The two bacteria (i.e., Pseudomonas aeruginosa, Pseudomonas fluorescents, Enterococcus species and Streptococcus) are uniformly distributed on the prepared petri dishes; each 8 petri dishes with Pseudomonas aeruginosa, Pseudomonas fluorescents, Enterococcus species and Streptococcus.

6. The socks and dishcloth fabric samples treated with Azadirachta indica oil solution are put on the petri dishes. This includes both unwashed and washed samples.

7. All the agar plates are incubated for $24 \mathrm{~h}$ at $37^{\circ} \mathrm{C}$.

8. After $24 \mathrm{~h}$ the agar plates are assessed visually.

\section{B) Procedure for soil burial test}

Azadirachta indica oil treated and untreated cotton fabric samples are buried in standard atmospheric soil for 28-30 days and the strength loss is compared.

\section{Results and Discussion}

The antibacterial property of Azadirachta indica oil treated socks and dishcloths were studied by means of the agar plate test and the growth difference of Pseudomonas species (Pseudomonas aeruginosa and Pseudomonas fluorescents) and coccus species (Enterococcus species and Streptococcus) around the treated and untreated fabric samples was observed. The result obtained from the test method is shown below. Untreated sample showed growth of bacteria on the plate around their perimeter. In this study the extracted Azadirachta indica oil is obtained by extraction with ethanol solvent using soxhlet apparatus. In addition, different curing temperatures are used for fixation to study the effect of curing temperature on antimicrobial activity of treated fabric samples. In all the cases the differences observed are negligible (Figure 1).

In addition to the agar plate test the result from soil burial test showed a difference in the antibacterial activity based on strength loss [4-6]. Accordingly both the buried socks and kitchen clothes showed minimum strength loss (less bacterial attack) as compare with untreated socks and kitchen fabric control sample. The treated socks and kitchen fabrics have shown increased resistance to bacteria [7-9]. Socks washed with Azadirachta indica oil and untreated control sale were used by the same person with the same shoes: the treated socks is used for 2 weeks while the untreated socks attacked by bad odor in 5 days, the same is for kitchen fabric (Figure 2).

\section{Conclusion}

The antibacterial finish of cotton fabric was done by using Azadirachta indica oil. Azadirachta indica oil selection is because of Azadirachta indica medicinal value, easily available and adds other properties like antioxidant and UV For studying antibacterial activity of Azadirachta indica Pseudomonas species (Pseudomonas aeruginos and Pseudomonas fluorescents) and coccus species (Enterococcus species and Streptococcus) were selected. The reason is socks are mostly affected by coccus species bacterias whereas kitchen fabrics are affected

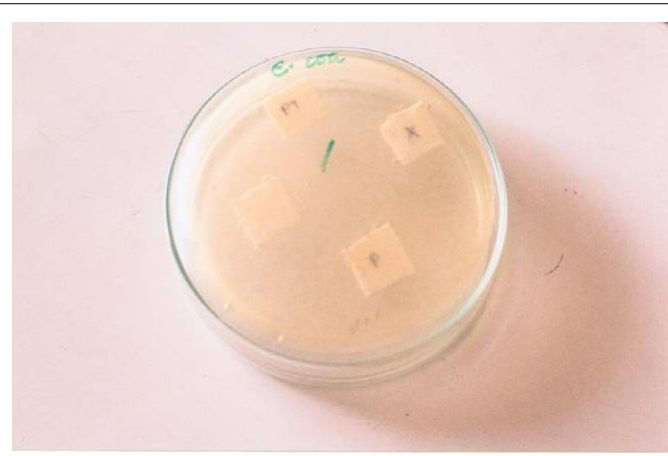

Figure 1: Antibacterial activity of Azadirachta indica oil treated dishcloth fabric against Pseudomonas species: Pseudomonas aeruginosa and Pseudomonas fluorescents. 


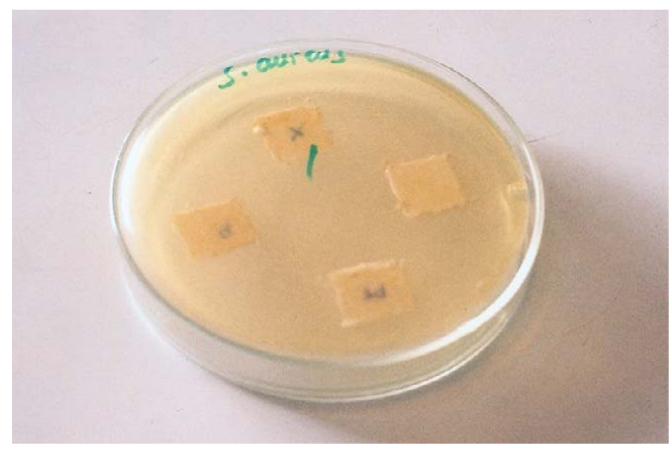

Figure 2: Antimicrobial activity of Azadirachta indica oil treated cotton socks fabric against coccus species: Enterococcus species and Streptococcus.

by Pseudomonas. The neem oil is obtained from neem leaf by ethanol solvent extraction using soxhlet apparatus. From the results on agar plate it can be concluded that though the Azadirachta indica treated socks and kitchen fabric samples show inhibition of the growth of bacteria the degree is low. This is associated with low concentration of Azadirachta indica below inhibitory used in the study. With the appropriate use of the appropriate concentration of Azadirachta indica oil it is possible to enhance the antibacterial property of Azadirachta indica oil treated cotton fabrics beyond what has been obtained in this study. Furthermore the soil burial test revealed that Azadirachta indica oil treated socks and kitchen fabrics have much higher antibacterial property than untreated control samples. Thus with ensured availability of appropriate selection matured neem leaf, proper technology for extraction of Azadirachta indica oil and appropriate testing facilities it is commercial to produce antibacterial socks and kitchen fabrics from Azadirachta indica (neem). This enhances the growth of the knowledge of using natural products as antibacterial agent which is still at its early stage. Further studies are required to be carried out to meet this target.

\section{References}

1. Gupta S, Gupta D (1994) Finishing' the Microbial Attack Vigo, Textile processing and properties, 1st (edn.), 251: 399-408.

2. Panchal P, Bajaj H, Maheshwari S (2013) Azadirachta indica (NEEM): antibacterial effects against Escherichia coli and Salmonella. Journal of Pharmacy and Research 1: 18-21.

3. Ramachandran T, Rajendrakumar K, Rajendran R (2004) Antimicrobial textilesan overview' IEJ 84: 42-47.

4. Zhang Y (2002) Applications of Natural Silk Protein Sericin in Biomaterials. Biotechnology Advances 20: 91-100.

5. Bokhari MH, Aslam KM, Neem (1985) A useful tree in Northern Nigeria. Annals of Borno 2: 83-86.

6. Akol AM, Sithanantham S, Varela AM, Mueke JM, Okelo RO (2001) Evaluation of two neem insecticides for non-target effects on the larval parasitoids of the diamondback moth, Plutella xylostella L. Proceedings of the 4 th International Workshop.

7. Martinez MJ, Betancourt J, Alonso-Gonzalez N (1996) Screening of some medicinal plants for antimicrobial activity. J Ethnopharmacol 52: 171-174.

8. Parekh J, Chanda S (2007) In vitro antimicrobial activity and phytochemical analysis of some Indian medicinal plants. Turk J Biol 31: 53-58.

9. Asif M (2012) Antimicrobial Potential of Azadirachta indica against Pathogenic Bacteria and Fungi. Journal of Pharmacognosy and Phytochemistry 1: 78-83. 